\title{
Cross-national patterns of substance use disorder treatment and associations with mental disorder comorbidity in the WHO World Mental Health Surveys
}

\author{
Meredith G. Harris ${ }^{1,2}$, Chrianna Bharat ${ }^{3}$ (D) Meyer D. Glantz ${ }^{4}$, Nancy A. Sampson ${ }^{5}$, Ali Al-Hamzawi ${ }^{6}$, \\ Jordi Alonso ${ }^{7,8}$, Ronny Bruffaerts', José Miguel Caldas de Almeida ${ }^{10}$, Alfredo H. Cia ' ', \\ Giovanni de Girolamo ${ }^{12}$, Silvia Florescu ${ }^{13}$, Oye Gureje ${ }^{14}$, Josep Maria Haro ${ }^{15}$, Hristo Hinkov ${ }^{16}$, \\ Elie G. Karam ${ }^{17,18,19}$, Georges Karam ${ }^{20,21}$, Sing Lee ${ }^{22}$, Jean-Pierre Lépine ${ }^{23}$, Daphna Levinson ${ }^{24}$, \\ Victor Makanjuola $^{25}$, John McGrath ${ }^{26,27,28}$ (D), Zeina Mneimneh ${ }^{29}$, Fernando Navarro-Mateu ${ }^{30}$ (D), \\ Marina Piazza ${ }^{31}$, José Posada-Villa ${ }^{32}$, Charlene Rapsey ${ }^{33}$, Hisateru Tachimori ${ }^{34}$, \\ Margreet ten Have ${ }^{35}$, Yolanda Torres ${ }^{36}$, Maria Carmen Viana ${ }^{37}$, Somnath Chatterji ${ }^{38}$, Alan \\ M. Zaslavsky ${ }^{39}$, Ronald C. Kessler ${ }^{39}$ \& Louisa Degenhardt ${ }^{40}$ iD behalf of the World Health \\ Organization's World Mental Health Surveys collaborators
}

\section{ABSTRACT}

Aims To examine cross-national patterns of 12-month substance use disorder (SUD) treatment and minimally adequate treatment (MAT), and associations with mental disorder comorbidity. Design Cross-sectional, representative household surveys. Setting Twenty-seven surveys from 25 countries of the WHO World Mental Health Survey Initiative. Participants A total of 2446 people with past-year DSM-IV SUD diagnoses (alcohol or illicit drug abuse and dependence). Measurements Outcomes were SUD treatment, defined as having either received professional treatment or attended a self-help group for substance-related problems in the past 12 months, and MAT, defined as having either four or more SUD treatment visits to a health-care professional, six or more visits to a non-health-care professional or being in ongoing treatment at the time of interview. Covariates were mental disorder comorbidity and several socio-economic characteristics. Pooled estimates reflect country sample sizes rather than population sizes. Findings Of respondents with pastyear SUD, 11.0\% [standard error $(\mathrm{SE})=0.8$ ] received past 12-month SUD treatment. SUD treatment was more common among people with comorbid mental disorders than with pure SUDs $(18.1 \%, \mathrm{SE}=1.6$ versus $6.8 \%$, SE $=0.7)$, as was MAT $(84.0 \%, \mathrm{SE}=2.5$ versus $68.3 \%, \mathrm{SE}=3.8)$ and treatment by health-care professionals $(88.9 \%, \mathrm{SE}=1.9$ versus $78.8 \%$, $\mathrm{SE}=3.0$ ) among treated SUD cases. Adjusting for socio-economic characteristics, mental disorder comorbidity doubled the odds of SUD treatment [odds ratio $(\mathrm{OR})=2.34 ; 95 \%$ confidence interval $(\mathrm{CI})=1.71-3.20$ ], MAT among SUD cases $(\mathrm{OR}=2.75 ; 95 \% \mathrm{CI}=1.90-3.97)$ and MAT among treated cases $(\mathrm{OR}=2.48$; 95\% CI = 1.23-5.02). Patterns were similar within country income groups, although the proportions receiving SUD treatment and MAT were higher in highthan low-/middle-income countries. Conclusions Few people with past-year substance use disorders receive adequate 12-month substance use disorder treatment, even when comorbid with a mental disorder. This is largely due to the low proportion of people receiving any substance use disorder treatment, as the proportion of patients whose treatment is at least minimally adequate is high.

Keywords Comorbidity, mental disorders, minimally adequate treatment, substance use disorders, treatment, World Mental Health Surveys.

Correspondence to: Meredith Harris, School of Public Health, The University of Queensland and Queensland Centre for Mental Health Research Level 3, Dawson House, The Park Centre for Mental Health Australia, Queensland, Australia. E-mail: meredith_harris@qcmhr.uq.edu.au Submitted 30 July 2018; initial review completed 3 October 2018; final version accepted 22 February 2019

\section{INTRODUCTION}

Substance use disorders (SUDs), including alcohol and illicit drug abuse and dependence, are conservatively estimated to affect $2.6 \%$ of the world's population each year [1]. SUDs were the eighth leading cause of riskattributable disability-adjusted life-years globally in 2016 and the fourth to fifth leading cause in socio-economically 
developed regions [2]. Despite the availability of effective interventions for SUD, few people with these disorders receive treatment and even fewer receive minimally adequate treatment (MAT); that is, an amount that could reasonably be expected to provide the opportunity to begin potentially effective intervention [1,3-6].

Among people with past-year SUDs, having a comorbid mental disorder increases the likelihood of receiving treatment [7-10]. Estimates suggest that more than $40 \%$ of people with past-year SUDs have a comorbid mental disorder, most commonly a mood or anxiety disorder [11,12]. SUD cases with comorbid mental disorders have a more severe and disabling course of illness, poorer social and clinical outcomes if under-treated, and more complications with treatment than those with pure SUDs [13]. Treatment guidelines recommend that when SUDs and mental disorders co-occur, each disorder should be treated in its own right [14]. Countries vary in their funding and organization of SUD services. High-income countries are more likely to have dedicated funding for specialized SUD services and to administer these separately from mental health services [13]. For these reasons, an understanding is needed of the extent to which people with past-year SUDs received 'SUD treatment' (i.e. for the purpose of treating an SUD), and how this differs according to comorbidity status and across countries.

Most population estimates of SUD treatment have come from the United States, showing that only $8-15 \%$ of people with past-year SUDs received SUD treatment in the preceding 12 months $[7,8]$. SUD treatment tended to be more common for SUD cases with comorbid mental disorders (10.5-42.0\% [15-17]) than those with pure SUDs (6.7$10 \%[17,18])$. People with past-year SUDs also had 1.33.4 times greater probability of receiving mental health treatment than SUD treatment, even if they did not have a comorbid mental disorder [7,15-18]. This may occur for several reasons. For example, people with pure SUDs may have sought mental health treatment because they perceived their substance use problem as a mental health problem; people with SUDs and comorbid mental disorders may perceive the latter as the most troubling. People with SUDs, regardless of comorbidity, may regard mental health services as more adequate, acceptable or available $[5,7,17,18]$. Co-occurring SUDs and mental disorders influence each other [13]; however, the extent to which treatment for a comorbid mental disorder will also be effective in alleviating the SUD is not known, and would probably vary greatly depending on the aetiology, severity and type of the comorbid disorder.

Reducing the burden of SUDs requires improvements in the coverage and quality of SUD treatment. In clinical samples, high-quality SUD treatment (as indicated by processbased measures of treatment intensity, therapeutic content and continuity) has been associated with better outcomes for people with SUDs [19-21]. In an analysis of population data from 26 countries in the World Health Organization's (WHO) World Mental Health Survey (WMHS) initiative [1], information about type and number of health-care visits was used to estimate MAT among people with pastyear SUDs who had received treatment for emotional or substance use problems in the previous 12 months. Only $7.1 \%$ of people with past-year SUDs received MAT, ranging from $1.0 \%$ in low-/lower-middle-income countries to $10.3 \%$ in high-income countries [1]. However, corresponding estimates among those who received SUD treatment specifically, and associations with mental disorder comorbidity, are lacking.

We examined cross-national patterns of 12-month SUD treatment among people with pure and comorbid past-year SUDs. Specific aims were to: (1) estimate the proportions receiving SUD treatment and MAT by comorbidity status and country income level; (2) examine the sectors in which people received SUD treatment and MAT, namely from health-care professionals and nonhealth-care professionals; and (3) examine potential associations of mental disorder comorbidity with SUD treatment and MAT.

\section{METHODS}

\section{Sample}

Data came from 27 surveys in 25 countries participating in the WMHS (Table 1). Five were classified as low- and lower-middle-income (Colombia, Iraq, Nigeria, China and Peru), six as upper-middle-income (Brazil, Bulgaria, Colombia, Lebanon, Mexico and Romania) and 16 as high-income (Argentina, Australia, Belgium, France, Germany, Israel, Italy, Japan, the Netherlands, New Zealand, Northern Ireland, Poland, Portugal, Spain, Spain-Murcia, and the United States). Each survey's interviewing sample size was determined by its available resources and data collection budget; however, all utilized a probability sample design for the selection of a representative sample of their target population, with the majority using multi-stage, clustered area probability designs. The weighted average response rate throughout all countries was $68.5 \%$ (Table 1 ).

SUDs were assessed with the WHO Composite International Diagnostic Interview (CIDI) version 3.0, a validated fully structured interview designed to generate life-time and 12-month diagnoses of mental disorders according to DSM-IV and ICD-10 criteria. The interview was developed in English and standardized protocols were used to adapt the CIDI for use in each participating country [22,23].

All respondents completed Part I of the CIDI, which contained a diagnostic assessment of core mental disorders. Respondents identified with a disorder during the Part 
Table 1 Survey characteristics.

\begin{tabular}{|c|c|c|c|c|c|c|}
\hline \multirow[b]{2}{*}{ Country $^{\mathrm{a}}$} & \multirow[b]{2}{*}{ Sample characteristics } & \multirow{2}{*}{$\begin{array}{l}\text { Field } \\
\text { dates }\end{array}$} & \multirow{2}{*}{$\begin{array}{l}\text { Age } \\
\text { range }\end{array}$} & \multicolumn{2}{|c|}{ Sample size } & \multirow{2}{*}{$\begin{array}{l}\text { Response } \\
\text { rate }\end{array}$} \\
\hline & & & & Part 1 & Part 2 & \\
\hline \multicolumn{7}{|c|}{ Low- and lower-middle-income countries } \\
\hline Colombia & $\begin{array}{l}\text { All urban areas of the country } \\
\text { (about } 73 \% \text { of the total national } \\
\text { population) }\end{array}$ & 2003 & $18-65$ & 4426 & 2381 & $87.7 \%$ \\
\hline Iraq & Nationally representative & $2006-7$ & $18-96$ & 4332 & 4332 & $95.2 \%$ \\
\hline Nigeria & $\begin{array}{l}21 \text { of the } 36 \text { states in the country } \\
\text { (approximately } 57 \% \text { of the national } \\
\text { population) }\end{array}$ & $2002-4$ & $18-100$ & 6752 & 2143 & $79.3 \%$ \\
\hline China & $\begin{array}{l}\text { Beijing and Shanghai metropolitan } \\
\text { areas }\end{array}$ & $2001-3$ & $18-70$ & 5201 & 1628 & $74.7 \%$ \\
\hline Peru & $\begin{array}{l}5 \text { urban areas of the country } \\
\text { (approximately } 38 \% \text { of the total } \\
\text { national population). }\end{array}$ & $2004-5$ & $18-65$ & 3930 & 1801 & $90.2 \%$ \\
\hline Total & & & & 24641 & 12285 & $83.7 \%$ \\
\hline \multicolumn{7}{|c|}{ Upper-middle-income countries } \\
\hline Brazil & São Paulo metropolitan area & $2005-8$ & $18-93$ & 5037 & 2942 & $81.3 \%$ \\
\hline Bulgaria & Nationally representative & $2002-6$ & $18-98$ & 5318 & 2233 & $72.0 \%$ \\
\hline Colombia (Medellin) & Medellin metropolitan area & 2011-12 & $19-65$ & 3261 & 1673 & $97.2 \%$ \\
\hline Lebanon & Nationally representative & $2002-3$ & $18-94$ & 2857 & 1031 & $70.0 \%$ \\
\hline Mexico & $\begin{array}{l}\text { All urban areas of the country } \\
\text { (approximately } 75 \% \text { of the total } \\
\text { national population) }\end{array}$ & $2001-2$ & $18-65$ & 5782 & 2362 & $76.6 \%$ \\
\hline Romania & Nationally representative & $2005-6$ & $18-96$ & 2357 & 2357 & $70.9 \%$ \\
\hline Total & & & & 24612 & 12598 & $77.2 \%$ \\
\hline \multicolumn{7}{|l|}{ High-income countries } \\
\hline Argentina & $\begin{array}{l}8 \text { largest urban areas of the } \\
\text { country: approximately } 50 \% \text { of } \\
\text { the total national population. }\end{array}$ & 2015 & $18-98$ & 3927 & 2116 & $77.3 \%$ \\
\hline Australia & Nationally representative & 2007 & $18-85$ & 8463 & 8463 & $60.0 \%$ \\
\hline Belgium & Nationally representative & $2001-2$ & $18-95$ & 2419 & 1043 & $50.6 \%$ \\
\hline France & Nationally representative & $2001-2$ & $18-97$ & 2894 & 1436 & $45.9 \%$ \\
\hline Germany & Nationally representative & $2002-3$ & $19-95$ & 3555 & 1323 & $57.8 \%$ \\
\hline Israel & Nationally representative & $2003-4$ & $21-98$ & 4859 & 4859 & $72.6 \%$ \\
\hline Italy & Nationally representative & $2001-2$ & $18-100$ & 4712 & 1779 & $71.3 \%$ \\
\hline Japan & 11 metropolitan areas & $2002-6$ & $20-98$ & 4129 & 1682 & $55.1 \%$ \\
\hline The Netherlands & Nationally representative & $2002-3$ & $18-95$ & 2372 & 1094 & $56.4 \%$ \\
\hline New Zealand & Nationally representative & $2004-5$ & $18-98$ & 12790 & 7312 & $73.3 \%$ \\
\hline Northern Ireland & Nationally representative & $2005-8$ & $18-97$ & 4340 & 1986 & $68.4 \%$ \\
\hline Poland & Nationally representative & 2010-11 & $18-65$ & 10081 & 4000 & $50.4 \%$ \\
\hline Portugal & Nationally representative & $2008-9$ & $18-81$ & 3849 & 2060 & $57.3 \%$ \\
\hline Spain & Nationally representative & $2001-2$ & $18-98$ & 5473 & 2121 & $78.6 \%$ \\
\hline Spain-Murcia & Murcia region & 2010-12 & $18-96$ & 2621 & 1459 & $67.4 \%$ \\
\hline United States & Nationally representative & $2001-3$ & $18-99$ & 9282 & 5692 & $70.9 \%$ \\
\hline Total & & & & 85766 & 48425 & $63.1 \%$ \\
\hline Overall sample & & & & 135019 & 73308 & $68.5 \%$ \\
\hline
\end{tabular}

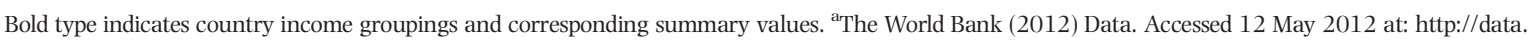
world bank.org/country. Some of the WMH countries have moved into new income categories since the surveys were conducted. The income groupings above reflect the status of each country at the time of data collection. ${ }^{\mathrm{b}}$ The response rate is calculated as the ratio of the number of households in which an interview was completed to the number of households originally sampled, excluding from the denominator households known not to be eligible either because of being vacant at the time of initial contact or because the residents were unable to speak the designated languages of the survey.

I assessment and a probability sample of other Part I respondents were administered Part II, which assessed disorders of secondary interest and correlates. Analyses in the current study are restricted to respondents with a past-year SUD (DSM-IV diagnoses of alcohol or illicit drug abuse or dependence). 
All surveys were administered face-to-face by trained lay interviewers. Interviewer training and quality control procedures were standardized across surveys [24]. Informed consent was obtained according to protocols endorsed by local institutional review boards.

\section{Definitions of SUD treatment and minimally adequate SUD treatment}

Among participants with an SUD, SUD treatment was defined as having either received treatment from a healthcare professional or attended a self-help group for substance-related problems at any time in the past year. Treatment was classified as having come from a healthcare professional if a speciality mental health professional (psychiatrist, psychologist, other mental health professional in any setting, social worker or counsellor in a mental health speciality treatment setting or a mental health hotline) or general professional (primary care doctor, other medical doctor or other health-care professional in a medical setting) had been consulted. If only non-medical professionals (social worker or counsellor in a non-medical setting, religious or spiritual adviser or healer) or self-help groups had been consulted, treatment was classified as non-health care.

Among people who received any SUD treatment, minimally adequate treatment (MAT) was defined as having either at least four treatment visits to a health-care professional, at least six visits to a non-health-care professional or self-help group or being in continuing treatment at the time of interview. These thresholds represent the minimum number of visits reasonably expected to provide opportunity to instigate the necessary steps at the beginning of any SUD or mental disorder intervention, including patient's report of symptoms, diagnosis, formulation of treatment plan, presentation of diagnosis and plan to the patient, patient acceptance of the plan, for intervention to be started and for the patient to experience and make at least some commitment to the intervention [6].

\section{Comorbid mental disorders}

To investigate the association of a comorbid mental disorder with receipt of SUD treatment, participants with a past-year diagnosis of major depressive disorder, generalized anxiety disorder, bipolar disorders, panic disorder, social disorder, specific disorder and agoraphobia were identified. Standardized diagnostic hierarchy rules among these disorders were applied, where appropriate.

\section{Statistical methods}

All analyses were based on weighted data to make samples representative of the target population's sociodemographic characteristics. Individual-level weights were used to adjust for differences in probability of selection, and to match the socio-demographics of the sample to those of the population. To adjust for differential sampling into Part II, Part II respondents were weighted by the inverse of their probability of selection into Part II, equalizing prevalence estimates in the weighted Part II and Part I samples. Standard errors were estimated using Taylor Series linearization taking into account weighting, clustering and stratification. Prevalence estimates were produced in PROC SURVEYFREQ, and logistic regression analyses in PROC SURVEYLOGISTIC, both implemented in SAS version 9.0.

Surveys are combined for purposes of pooled estimates based on sample sizes, rather than sizes of the populations of the countries surveyed. Pooled prevalence estimates therefore represent the weighted mean across our surveys, where weights are based on survey sample size. Furthermore, all regression models included dummy control variables for survey so that coefficients for other predictors could be interpreted as pooled within-survey coefficients. This approach, which implicitly assumed that withinsurvey slopes were constant across surveys, was implemented because the degree of survey-level variability attributable to the parameter of main interest was found to be modest, and allowing (in a random-slope model) for inter-country variation in that slope had little effect on the mean slope estimate and its standard error.

To test for differences between SUD only and SUD and at least one comorbid mental disorder, and high- and low-middle-income countries, in relation to the key variables of interest related to the aims of the paper, $\chi^{2}$ tests were applied. Logistic regression analyses were conducted to predict 12-month SUD treatment and MAT among all people with a past-year SUD, and MAT among the subset of past-year SUD cases with any 12-month SUD treatment. To investigate the associations of comorbid mental disorders with SUD treatment, we defined a single indicator variable capturing the presence of any past-year depression, bipolar, panic, generalized anxiety, social, specific or agoraphobia disorder. Due to low counts within select disorders, modelling of individual mental disorder indicators was not feasible.

Other covariates included sex, age at interview $(<25,25-34,35-44$ and 45+), personal income defined in within-country quartiles (low, low-average, highaverage and high), marriage status (never married, married/cohabitating, separated/widowed/divorced), education level defined within-country (low, low-average, high-average and high) [25] and country income level [high- and low-/low-middle/upper-middle (or 'low-middle' levels combined due to low statistical power) from Table 1] of the survey country or region. We conducted analyses with all countries pooled, and subgroup analyses by country income level; however, there was not enough statistical power to make separate estimates for each country. 
We conducted sensitivity analyses among a subset of surveys that captured information regarding physical health comorbidities in a consistent manner (1986 respondents with past-year SUD). The physical comorbidities included past-year presence of any back or neck problems, headaches, chronic pain, allergies, diabetes, ulcer(s), HIV infection, epilepsy or seizures, and cancer. We also included life-time presence of heart disease, hypertension, asthma and chronic lung disease, as these conditions are typically chronic and require ongoing management or treatment. We modelled the number of past-year physical comorbidities as: exactly one, exactly two and three or more.

Parameter coefficients and standard errors are reported as odds ratios (OR) and 95\% confidence intervals (CIs) with statistical significance evaluated using 0.05-level two-sided tests.

\section{RESULTS}

Among all countries, 2446 (2.6\%) people in the WMHS met criteria for a past-year SUD, with prevalence higher in high- $(3.0 \%)$ than in low-middle-income countries (1.9\%). Overall, approximately one in three people with a past-year SUD also had at least one other mental disorder in the same time-frame, with higher comorbidity among those in high- than in low-middle-income countries (Table 2).

\section{SUD treatment}

One in nine past-year SUD cases received SUD treatment in the past 12 months. Among past-year SUD cases, SUD treatment was twice as common in high- compared to low-middle-income countries, and among those with a comorbid mental disorder compared to those with a diagnosis of SUD only. This pattern was consistent in high- and lowmiddle-income countries.

\section{Minimally adequate treatment (MAT)}

Among those who received SUD treatment, more than three-quarters met MAT thresholds (Table 2). MAT was more common in high- than in low-middle-income countries, and among people with a comorbid disorder compared to those with a SUD only.

\section{SUD treatment professionals}

Most people with 12-month SUD treatment were treated by at least one health-care professional. The use of health-care professionals for treatment was more common among people with a comorbid disorder than among those with an SUD only across all countries and in high-income surveys. Among people who received SUD treatment from a health-care professional, most received MAT. MAT was more common in high-income countries than low-middle-income countries, and was more common among those with a comorbid disorder than among those with an SUD only in low-middle-income countries, but not in high-income countries.

The use of non-health-care professionals as the sole source of SUD treatment was uncommon. Levels of MAT from a non-health-care professional were higher among people with a comorbid disorder compared to those with a SUD only in both the pooled and high-income surveys.

Although there was no difference between country income groups in the proportion of SUD cases obtaining treatment from a health-care professional, MAT provision was more common for those treated by health-care professionals in high- than low-middle-income countries. Supporting information, Table S1 presents bivariate comorbid mental disorder odds ratios for all outcomes shown in Table 2.

\section{Comorbid mental disorder and SUD treatment}

Results from logistic regression analyses investigating the association of comorbid disorder with receipt of any SUD treatment and MAT are presented in Table 3 and Fig. 1. Adjusting for all socio-demographics, the presence of a comorbid disorder more than doubled the odds of receiving SUD treatment, MAT among SUD cases and MAT among treated cases. Consistent results were observed within country-level income groups.

In sensitivity analyses, after adjusting for number of past-year physical comorbidities, people with past-year comorbid mental disorder still had higher odds of SUD treatment $(\mathrm{OR}=1.75 ; 95 \mathrm{CI}=1.27-2.40)$ and MAT $(\mathrm{OR}=2.13 ; 95 \% \mathrm{CI}=1.47-3.09)$ (details available upon request).

Additional models investigated potential differences in correlates of SUD treatment by type of professional. These, along with the full model results from analyses shown in Table 3, are shown in Supporting information, Tables S2S10. These show that the patterns observed in the main analyses were all similar for those receiving SUD treatment from a health-care professional specifically and, despite small numbers, were generally similar for those receiving non-health-care treatment only.

\section{DISCUSSION}

We are aware of no previous comparative cross-national data on SUD treatment. We found SUD treatment among past-year SUD cases to be low across all countries studied (11.0\%). Most treated cases received MAT but, because of the low coverage, only $8.5 \%$ of all SUD cases received adequate SUD treatment. MAT was more common among 


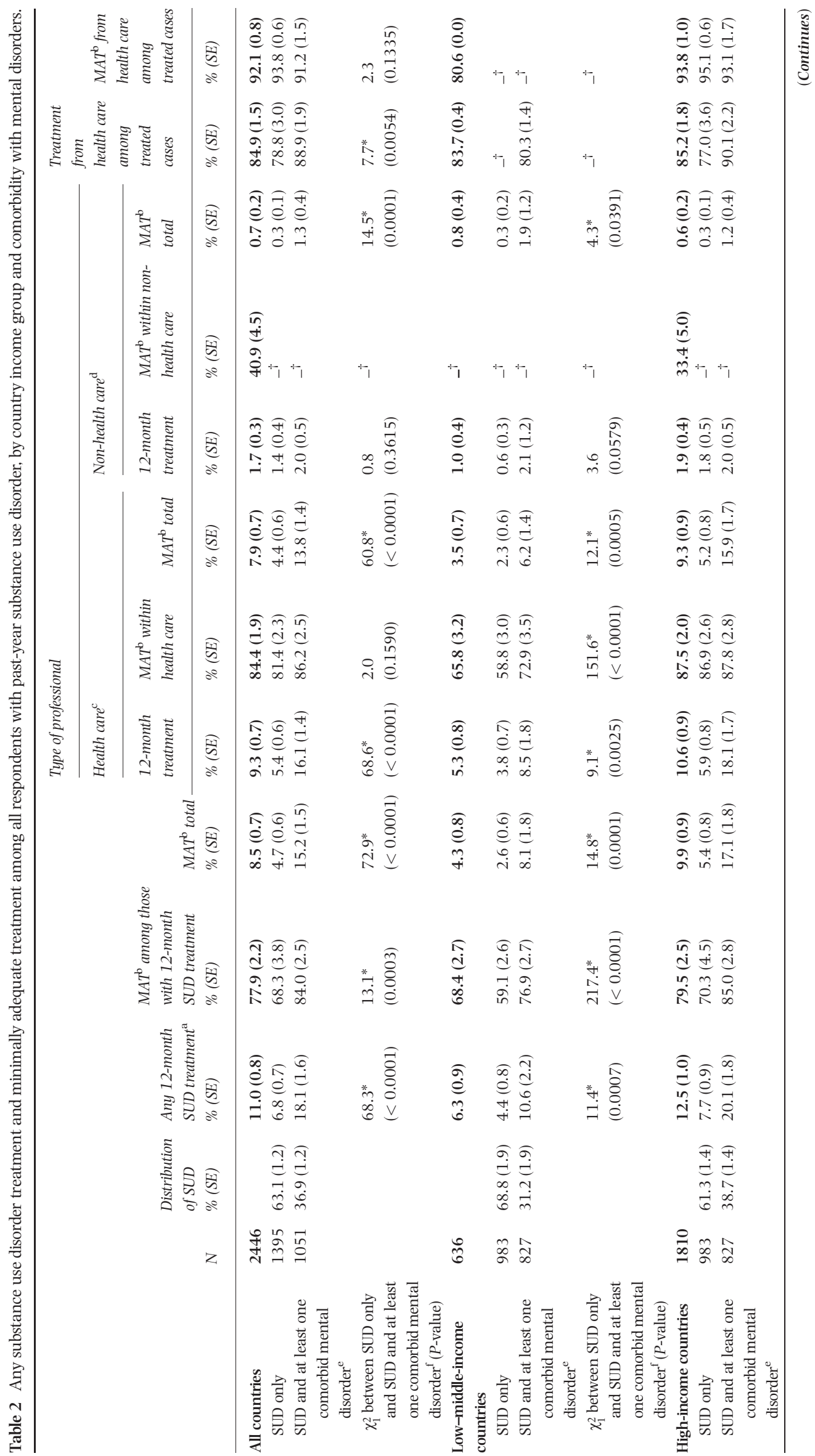




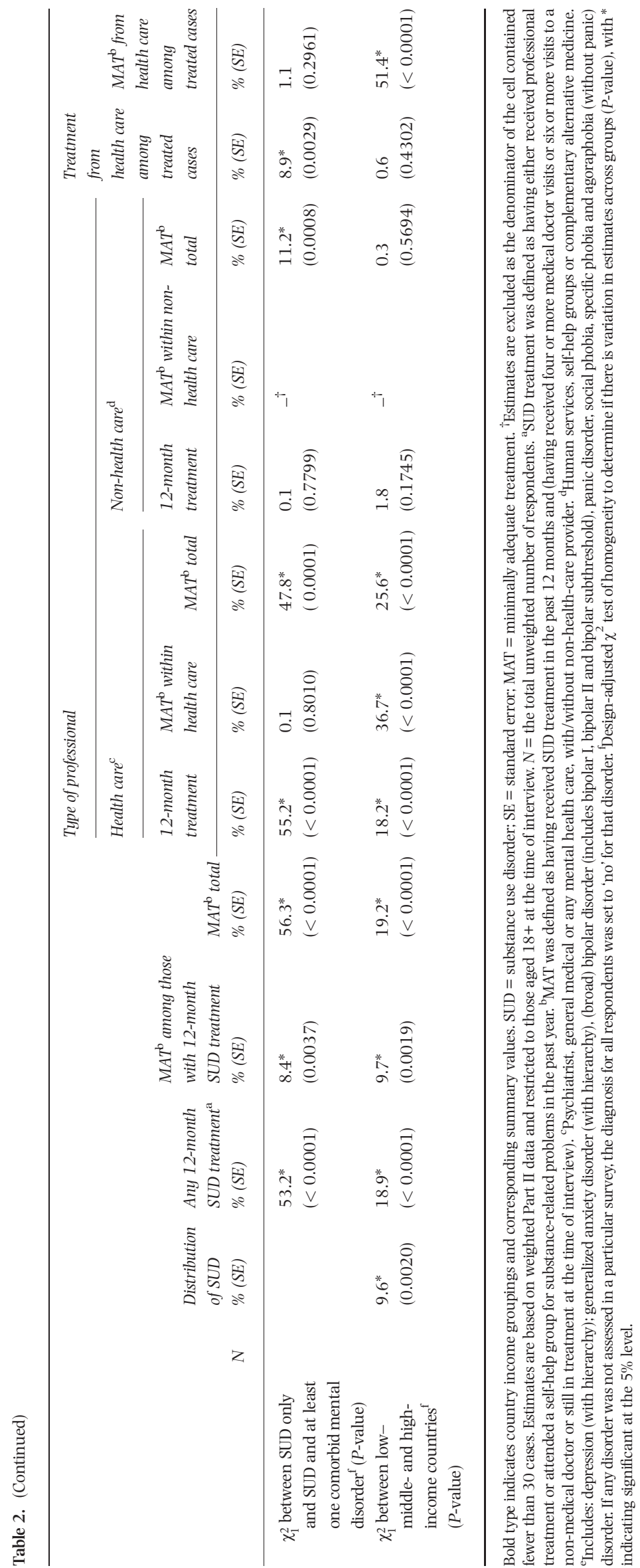


Table 3 Logistic regression results investigating association between having a comorbid mental disorder and receiving "any" and 'minimally adequate' 12 -month substance use disorder treatment.

\begin{tabular}{|c|c|c|c|c|c|}
\hline \multirow[b]{3}{*}{ Response } & \multirow[b]{3}{*}{ Among those with ... } & \multicolumn{4}{|c|}{ Comorbid mental disorder ${ }^{\mathrm{a}}$ (Ref: no) } \\
\hline & & \multicolumn{2}{|c|}{ Bivariate } & \multicolumn{2}{|c|}{ Multivariable $^{\mathrm{b}}$} \\
\hline & & OR & $(95 \% C I)$ & $O R$ & $(95 \% C I)$ \\
\hline \multicolumn{6}{|l|}{ All countries } \\
\hline Any 12 -month SUD treatment ${ }^{\mathrm{c}}$ & Past-year SUD ${ }^{\mathrm{d}}$ & $2.72^{*}$ & $(2.01-3.67)$ & $2.34^{*}$ & $(1.71-3.20)$ \\
\hline Minimally adequate treatment ${ }^{\mathrm{d}}$ & Any 12-month SUD treatment & $2.92^{*}$ & $(1.54-5.53)$ & $2.48^{*}$ & $(1.23-5.02)$ \\
\hline Minimally adequate treatment ${ }^{\mathrm{d}}$ & Past-year SUD ${ }^{\mathrm{d}}$ & $3.34^{*}$ & $(2.35-4.74)$ & $2.75^{*}$ & $(1.90-3.97)$ \\
\hline \multicolumn{6}{|l|}{ Low-middle-income countries } \\
\hline Any 12-month SUD treatment ${ }^{\mathrm{c}}$ & Past-year SUD ${ }^{\mathrm{d}}$ & $2.40^{*}$ & $(1.36-4.21)$ & $2.44^{*}$ & $(1.38-4.32)$ \\
\hline Minimally adequate treatment ${ }^{\mathrm{d}}$ & Any 12-month SUD treatment & e & & e & \\
\hline Minimally adequate treatment ${ }^{\mathrm{d}}$ & Past-year SUD ${ }^{\mathrm{d}}$ & $2.82^{*}$ & $(1.48-5.39)$ & $2.97^{*}$ & $(1.55-5.69)$ \\
\hline \multicolumn{6}{|l|}{ High-income countries } \\
\hline Any 12 -month SUD treatment ${ }^{\mathrm{c}}$ & Past-year SUD ${ }^{\mathrm{d}}$ & $2.71^{*}$ & $(1.91-3.84)$ & $2.29^{*}$ & $(1.60-3.29)$ \\
\hline Minimally adequate treatment ${ }^{\mathrm{d}}$ & Any 12-month SUD treatment & $3.14^{*}$ & $(1.48-6.67)$ & $2.49^{*}$ & $(1.09-5.68)$ \\
\hline Minimally adequate treatment ${ }^{\mathrm{d}}$ & Past-year SUD ${ }^{\mathrm{d}}$ & $3.29^{*}$ & $(2.21-4.91)$ & $2.68^{*}$ & $(1.75-4.10)$ \\
\hline
\end{tabular}

SUD = substance use disorder; $\mathrm{OR}=$ odds ratio; $\mathrm{CI}=$ confidence interval *Significant at the $5 \%$ significance level. All logistic regression analyses are based on weighted Part II data and include survey dummy variables. ${ }^{a}$ Includes: depression (with hierarchy); generalized anxiety disorder (with hierarchy), (broad) bipolar disorder (bipolar I, bipolar II and bipolar subthreshold), panic disorder, social phobia, specific phobia and agoraphobia (without panic) disorder ${ }^{b}$ Multivariable models adjust for age $(<25$ years, 25-34 years, 35-44 years and 45+ years), gender, income level (survey-specific levels defined as low, low-average, high-average and high), marriage status (never married, married/cohabitating and separated/widowed/divorced) and education level (survey-specific levels defined as low, low-average, high-average and high). In the models including all countries, country income level (low-middle and high) was also included. ${ }^{c}$ Any SUD treatment was defined as having either received professional treatment or attended a self-help group for substance-related problems in the past year. ${ }^{\mathrm{d}}$ Minimally adequate treatment is defined as having received SUD-specific professional treatment in the past 12 months and (having received four or more medical doctor visits or six or more visits to a non-medical doctor or still in treatment at the time of interview). ${ }^{\mathrm{e}}$ Analyses excluded as the denominator contained fewer than 50 cases.

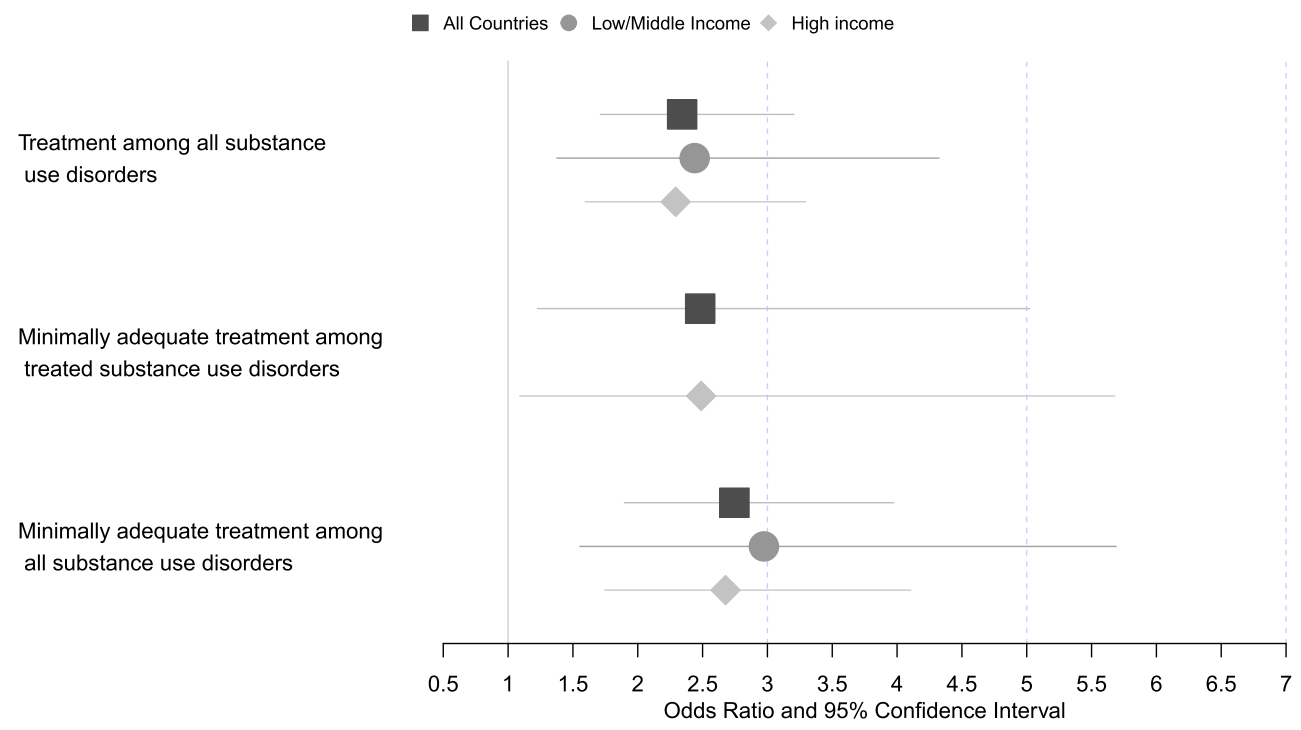

Figure I Forest plot with 95\% confidence intervals for odds ratios of comorbid mental disorder (reference = no) associated with receipt of any treatment among all substance use disorders (SUDs), minimally adequate treatment (MAT) among treated SUDs and MAT among all SUDs, for all countries combined (square), and by low-middle-income (circle) and high-income (diamond) countries (reference line at I); note: there were not enough cases to analyse MAT among treated SUDs in low-/middle-income countries only, so no estimate is provided. [Colour figure can be viewed at wileyonlinelibrary.com]

SUD cases with comorbid mental disorders, compared to cases with pure SUDs, due to the higher proportions receiving any SUD treatment and receiving MAT once treatment had started. These patterns were similar within country income groups, even though SUD treatment and MAT were twice as common among SUD cases from highincome countries compared to low-middle-income countries. 


\section{Limitations}

There were important limitations. First, our MAT criteria would ideally have included receipt of potentially beneficial pharmacological treatments for SUDs (e.g. naltrexone for alcohol dependence [26] and opioid substitution therapy for opioid dependence [25]). However, medication use (types, timing, duration and adherence) was not covered in sufficient detail in the WMHS. The criteria counted visits to health-care professionals who are able to prescribe and monitor medications.

Second, due to low counts, the individual impact of specific combinations of SUDs and mental disorders on receipt of SUD treatment could not be investigated. The coefficient representing the impact of any comorbid mental disorder represents the mean effect of any and all disorders. Patterns of treatment may vary according to different combinations of diagnoses [27] or other latent structures [6,28]. This is an avenue for future work.

Third, we assumed that respondents could reliably identify that they had received treatment for substancerelated problems. Studies have found acceptable levels of agreement between self-reported use of substance use services and administrative records or other independent sources among people with substance use problems or disorders [29-33], with better agreement for aggregate measures than for detailed measures [32,33] and poorer agreement among high-volume service users [29,30].

Fourth, to our knowledge, the predictive validity of the MAT criteria used in this study has not been established.

Fifth, the comparatively lower disability associated with substance abuse compared to dependence may, in part, explain the low treatment proportions; however, there was not enough statistical power to conduct separate analyses for abuse and dependence.

Sixth, there may be between-country variations in willingness to report use of various substances, due to legal frameworks, cultural norms and other factors.

Seventh, the number of reported visits used in evaluating MAT may potentially include visits made for mental health problems other than SUDs, so the proportion receiving MAT may be even lower than reported here.

Finally, our sensitivity analyses included many, but not all, physical conditions (e.g. stroke, liver problems) that are prevalent among people with SUDs or may affect SUD treatment [34,35]. General limitations of the WMHS are discussed in detail elsewhere $[1,36]$.

\section{Implications}

Few past-year SUD cases received 12-month SUD treatment. Our estimates of 12-month SUD treatment in highincome countries were broadly similar to independent US estimates for people with any SUD (12.5 versus $8-15 \%$
$[7,8]$ ), comorbid SUD and mental disorder (19.9 versus $10.5-42.0 \%$ [15-17]) and SUD only (4.8 versus $6.7 \%-10 \%[17,18])$. Equivalent comparisons for lowmiddle-income countries were not possible. Reasons for low SUD treatment proportions are many and varied [37-44]. Systemic factors (e.g. low policy priority, scarcity of services and appropriately trained professionals, lack of community-based care options, out-of-pocket payment models) and community factors (e.g. stigmatizing community attitudes) are especially relevant in low-middleincome countries [45-47].

Only $8.5 \%$ of past-year SUD cases received MAT, lower than has been reported for depression [36] but similar to anxiety disorders [48] (noting that the MAT criteria in those studies [36,48] took account of medication use which the current study could not). This was due largely to the low proportion receiving any SUD treatment, as the proportion of treated SUD cases who received MAT was high. A US study showed that people with SUDs had more treatment visits (median 6.6) than people with mental disorders (2.4-6.0, depending on disorder) [4]. Together, these findings could suggest that people with SUDs who commence treatment are committed to obtaining a positive outcome and therefore persist with it.

In the pooled professional samples, lower proportions of SUD treatment and MAT among pure SUD cases could indicate that this group are at greater risk of undertreatment. However, SUD cases with comorbid mental disorders have worse clinical presentation and outcomes [13], and are more likely to report unmet treatment needs $[42,49]$. Moreover, longitudinal studies show that people with SUDs who do not access treatment have, on average, less severe disorders and more favourable outcomes than treatment users, suggesting that many people appropriately self-select for treatment [50,51]. Further examination of the relationship between clinical characteristics of SUDs (e.g. comorbidity, severity, persistence and disability) and recent and life-time treatment patterns may help to identify those who should be the focus of policy and service responses to reduce the treatment gap for SUDs.

SUD treatment and MAT proportions in high-income countries were double those in low-middle-income countries, consistent with other evidence of SUD intervention coverage [52]. Moreover, in low-middle-income countries, the proportion receiving MAT was lower for those with pure, compared to comorbid, SUDs. The WHO Mental Health Gap Action Programme (mhGAP) Intervention Guide [53,54] has identified evidence-based interventions for SUDs that could feasibly be scaled-up in high- and low-middle-income countries. These include: selfmonitoring of high-risk behaviours for substance abuse; guideline-concordant pharmacological and psychological management of alcohol use disorders; and methadone maintenance therapy for opioid dependence and 
buprenorphine as opioid substitution therapy [55]. In lowmiddle-income countries specifically, there is good evidence that contextually appropriate regulatory and legal controls can reduce alcohol use and associated harms [56]. Preventive and treatment interventions - e.g. integrating awareness-raising of alcohol and drug misuse into the work-place and collaborative community-based care-are supported by good evidence from high-income countries but require more robust evidence from low-middle-income settings [55,56]. Scaling-up will require significant investment to increase system capacity, especially in countries with under-developed SUD treatment services and without substance use policies [39,47]. Improving work-force availability and training are critical to improving detection and quality of care of SUDs [38]; in contexts where specialist skills are scarce, task sharing and transitioning clinical specialists from direct service provision to supervisory roles may help to build capacity [55].

\section{CONCLUSIONS}

Improving treatment coverage and adequacy for SUDs is a global health priority [57]. We found that few people with past-year SUDs received MAT, even when comorbid with a mental disorder. Scaling-up of evidence-based interventions, informed by more robust evidence of population need and intervention efficacy in low-middle-income settings, could help address these treatment gaps.

\section{Declaration of interests}

In the past three years, R.C.K. received support for his epidemiological studies from Sanofi Aventis; was a consultant for Johnson \& Johnson Wellness and Prevention, Sage Pharmaceuticals, Shire, Takeda; and served on an advisory board for the Johnson \& Johnson Services Inc. Lake Nona Life Project. R.C.K. is a co-owner of DataStat, Inc., a market research firm that carries out healthcare research. In the past three years, L.D. has received investigator-initiated untied educational grants for studies of opioid medications in Australia from Indivior, Mundipharma and Seqirus. All other authors have nothing to disclose.

\section{Acknowledgements}

The World Health Organization World Mental Health (WMH) Survey Initiative is supported by the United States National Institute of Mental Health (NIMH; R01 MH070884), the John D. and Catherine T. MacArthur Foundation, the Pfizer Foundation, the United States Public Health Service (R13-MH066849, R01-MH069864 and R01 DA016558), the Fogarty International Center (FIRCA R03-TW006481), the Pan American Health Organization, Eli Lilly and Company, Ortho-McNeil Pharmaceutical Inc., GlaxoSmithKline, and Bristol-Myers Squibb. We thank the staff of the WMH Data Collection and Data Analysis Coordination Centres for assistance with instrumentation, fieldwork and consultation on data analysis. None of the funders had any role in the design, analysis, interpretation of results, or preparation of this paper. The views and opinions expressed in this report are those of the authors and should not be construed to represent the views of the World Health Organization, other sponsoring organizations, agencies, or governments , and do not necessarily represent the views, official policy or position of the US Department of Health and Human Services or any of its affiliated institutions or agencies. M.D.G.'s role in this study is through his involvement as a Science Officer on U01-MH60220. He had no involvement in the other cited grants. The 2007 Australian National Survey of Mental Health and Wellbeing is funded by the Australian Government Department of Health and Ageing. The Argentina survey-Estudio Argentino de Epidemiología en Salud Mental (EASM) — was supported by a grant from the Argentinian Ministry of Health (Ministerio de Salud de la Nación). The São Paulo Megacity Mental Health Survey is supported by the State of São Paulo Research Foundation (FAPESP) Thematic Project Grant 03/00204-3. The Bulgarian Epidemiological Study of common mental disorders EPIBUL is supported by the Ministry of Health and the National Center for Public Health Protection. The Chinese World Mental Health Survey Initiative is supported by the Pfizer Foundation. The Colombian National Study of Mental Health (NSMH) is supported by the Ministry of Social Protection. The Mental Health Study MedellínColombia was carried out and supported jointly by the Center for Excellence on Research in Mental Health (CES University) and the Secretary of Health of Medellín. The ESEMeD project is funded by the European Commission [Contracts QLG5-1999-01042; SANCO 2004123, and EAHC 20081308) (the Piedmont Region (Italy)], Fondo de Investigación Sanitaria, Instituto de Salud Carlos III, Spain (FIS 00/0028), Ministerio de Ciencia y Tecnología, Spain (SAF 2000-158-CE), Generalitat de Catalunya (2017 SGR 452; 2014 SGR 748), Instituto de Salud Carlos III (CIBER CB06/02/0046, RETICS RD06/0011 REM-TAP) and other local agencies and by an unrestricted educational grant from GlaxoSmithKline. Implementation of the Iraq Mental Health Survey (IMHS) and data entry were carried out by the staff of the Iraqi MOH and MOP with direct support from the Iraqi IMHS team with funding from both the Japanese and European Funds through the United Nations Development Group Iraq Trust Fund (UNDG ITF). The Israel National Health Survey is funded by the Ministry of Health with support from the Israel National Institute for Health Policy and Health Services Research and the National Insurance Institute of Israel. The World Mental Health Japan (WMHJ) Survey is supported by the Grant for Research on Psychiatric and Neurological Diseases 
and Mental Health (H13-SHOGAI-023, H14-TOKUBETSU026, H16-KOKORO-013, H25-SEISHIN-IPPAN-006) from the Japan Ministry of Health, Labour and Welfare. The Lebanese Evaluation of the Burden of Ailments and Needs Of the Nation (L.E.B.A.N.O.N.) is supported by the Lebanese Ministry of Public Health, the WHO (Lebanon), National Institute of Health/Fogarty International Center (R03 TW006481-01), anonymous private donations to IDRAAC, Lebanon and unrestricted grants from Algorithm, AstraZeneca, Benta, Bella Pharma, Eli Lilly, Glaxo Smith Kline, Lundbeck, Novartis, OmniPharma, Pfizer, Phenicia, Servier and UPO. The Mexican National Comorbidity Survey (MNCS) is supported by The National Institute of Psychiatry Ramon de la Fuente (INPRFMDIES 4280) and by the National Council on Science and Technology (CONACyT-G30544- H), with supplemental support from the Pan American Health Organization (PAHO). Te Rau Hinengaro: the New Zealand Mental Health Survey (NZMHS) is supported by the New Zealand Ministry of Health, Alcohol Advisory Council, and the Health Research Council. The Nigerian Survey of Mental Health and Wellbeing (NSMHW) is supported by the WHO (Geneva), the WHO (Nigeria) and the Federal Ministry of Health, Abuja, Nigeria. The Northern Ireland Study of Mental Health was funded by the Health and Social Care Research and Development Division of the Public Health Agency. The Peruvian World Mental Health Study was funded by the National Institute of Health of the Ministry of Health of Peru. The Polish project Epidemiology of Mental Health and Access to Care-EZOP Project (PL 0256) was supported by Iceland, Liechtenstein and Norway through funding from the EEA Financial Mechanism and the Norwegian Financial Mechanism. The EZOP project was cofinanced by the Polish Ministry of Health. The Portuguese Mental Health Study was carried out by the Department of Mental Health, Faculty of Medical Sciences, NOVA University of Lisbon, with the collaboration of the Portuguese Catholic University, and was funded by Champalimaud Foundation, Gulbenkian Foundation, Foundation for Science and Technology (FCT) and Ministry of Health. The Romania WMH study projects 'Policies in Mental Health Area' and 'National Study regarding Mental Health and Services Use' were carried out by National School of Public Health and Health Services Management (former National Institute for Research and Development in Health), with technical support from Metro Media Transilvania, the National Institute of Statistics-National Centre for Training in Statistics, SC, Cheyenne Services SRL, Statistics Netherlands and were funded by Ministry of Public Health (former Ministry of Health) with supplemental support of Eli Lilly Romania SRL. The Psychiatric Enquiry to General Population in Southeast Spain-Murcia (PEGASUS-Murcia) Project has been financed by the Regional Health Authorities of Murcia (Servicio Murciano de Salud and Consejería de Sanidad y Política Social) and Fundación para la Formación e Investigación Sanitarias (FFIS) of Murcia. The US National Comorbidity Survey Replication (NCS-R) is supported by the National Institute of Mental Health (NIMH; U01-MH60220) with supplemental support from the National Institute of Drug Abuse (NIDA), the Substance Abuse and Mental Health Services Administration (SAMHSA), the Robert Wood Johnson Foundation (RWJF; Grant 044708) and the John W. Alden Trust. J.M. is supported by NHMRC Project grants (APP 1007677, APP 1099709) and a John Cade Fellowship (APP1056929). J.M. was supported by a Niels Bohr Professorship from the Danish National Research Foundation. L. D. is supported by an NHMRC Senior Principal Research Fellowship (no. 1135991) and NIDA NIH grant R01 DA044170-02. L.D. and C.B. are supported by an Australian National Health and Medical Research Council (NHMRC) project grant (no. 1081984). NDARC is supported by funding from the Australian Government Department of Health under the Drug and Alcohol Program. A complete list of all within-country and crossnational WMH publications can be found at http://www. hcp.med.harvard.edu/wmh/.

\section{Authors' affiliations}

School of Public Health, The University of Queensland, Herston, QLD, Australia, Queensland Centre for Mental Health Research, The Park Centre for Mental Health, QLD, Australia, ${ }^{2}$ National Drug and Alcohol Research Centre, University of New South Wales, Sydney, Australia, ${ }^{3}$ Department of Epidemiology, Services, and Prevention Research (DESPR), National Institute on Drug Abuse (NIDA), National Institutes of Health (NIH), Bethesda, MD, USA, ${ }^{4}$ Department of Health Care Policy, Harvard Medical School, Boston, MA, USA, ${ }^{5}$ College of Medicine, Al-Qadisiya University, Diwaniya Governorate, Iraq, ${ }^{6}$ Health Services Research Unit, IMIM-Hospital del Mar Medical Research Institute, Barcelona, Spain, ${ }^{7}$ CIBER en Epidemiología y Salud Pública (CIBERESP), Spain; Pompeu Fabra University (UPF), Barcelona, Spain, Universitair Psychiatrisch Centrum-Katholieke Universiteit Leuven (UPC-KUL), Campus Gasthuisberg, Leuven, Belgium, ${ }^{9}$ Lisbon Institute of Global Mental Health and Chronic Diseases Research Center (CEDOC), NOVA Medical School|Faculdade de Ciências Médicas, Universidade Nova de Lisboa, Lisbon, Portugal, ${ }^{10}$ Anxiety Disorders Center, Buenos Aires, Argentina," IRCCS Istituto Centro San Giovanni di Dio Fatebenefratelli, Brescia, $^{12}$ National School of Public Health, Management and Development, Bucharest, Romania, ${ }^{13}$ Department of Psychiatry, University College Hospital, Ibadan, Nigeria, ${ }^{14}$ Parc Sanitari Sant Joan de Déu, CIBERSAM, Universitat de Barcelona, Sant Boi de Llobregat, Barcelona, Spain, ${ }^{15}$ National Center of Public Health and Analyses, Sofia, Bulgaria, ${ }^{16}$ Department of Psychiatry and Clinical Psychology, Faculty of Medicine, Balamand University, Beirut, Lebanon, ${ }^{17}$ Department of Psychiatry and Clinical Psychology, St George Hospital University Medical Center, Beirut, Lebanon, ${ }^{18}$ Institute for Development Research Advocacy and Applied Care (IDRAAC), Beirut, Lebanon, ${ }^{19}$ Department of Psychiatry and Clinical Psychology, St George Hospital University Medical Center, Balamand University, Faculty of Medicine, Beirut, Lebanon, ${ }^{20}$ Institute for Development, Research, Advocacy and Applied Care (IDRAAC), Beirut, Lebanon, ${ }^{21}$ Department of Psychiatry, Chinese University of Hong Kong, Tai Po, Hong Kong, 22 Hôpital Lariboisière-Fernand Widal, Assistance Publique Hôpitaux de Paris, Universités Paris Descartes-Paris Diderot;INSERM UMR-S I |44, Paris, France, $^{23}$ Mental Health Services, Ministry of Health, Jerusalem, Israel, ${ }^{24}$ Department of Psychiatry, College of Medicine, University of Ibadan; University College Hospital, Ibadan, Nigeria, ${ }^{25}$ Queensland Centre for Mental Health Research, The Park Centre for Mental Health, Wacol, QLD, Australia, ${ }^{26}$ Queensland Brain Institute, University of Queensland, St Lucia, QLD, Australia, ${ }^{27}$ 
National Centre for Register-Based Research, Aarhus University, Aarhus, Denmark, ${ }^{28}$ Survey Research Center, Institute for Social Research, University of Michigan, Ann Arbor, MI, USA, ${ }^{29}$ UDIF-SM, Subdirección General de Planificación, Innovación y Cronicidad, Servicio Murciano de Salud, IMIB-Arrixaca, CIBERESP-, MurciaMurcia, Spain, ${ }^{30}$ Universidad Cayetano Heredia, Lima, Peru, Colegio Mayor de Cundinamarca University, Faculty of Social Sciences, Bogota, Colombia, ${ }^{32}$ Department of Psychological Medicine, University of Otago, Dunedin School of Medicine, Otago, New Zealand, ${ }^{33}$ National Institute of Mental Health, National Center for Neurology and Psychiatry, Kodaira, Tokyo, Japan, ${ }^{34}$ Trimbos-Instituut, the Netherlands Institute of Mental Health and Addiction, Utrecht, the Netherlands, ${ }^{35}$ Center for Excellence on Research in Mental Health, CES University, Medellin, Colombia, ${ }^{36}$ Department of Social Medicine, Postgraduate Program in Public Health, Federal University of Espírito Santo, Vitoria, Brazil, ${ }^{37}$ Department of Information, Evidence and Research, World Health Organization, Geneva, Switzerland, ${ }^{38}$ Department of Health Care Policy, Harvard Medical School, Boston, MA, USA ${ }^{39}$ and National Drug and Alcohol Research Centre, University of New South Wales, Sydney, NSW, Australia ${ }^{40}$

The WHO World Mental Health Survey collaborators are Sergio Aguilar-Gaxiola MD, PhD, Ali Al-Hamzawi MD, Mohammed Salih Al-Kaisy MD, Jordi Alonso MD, PhD, Laura Helena Andrade MD, PhD, Corina Benjet PhD, Guilherme Borges ScD, Evelyn J. Bromet PhD, Ronny Bruffaerts PhD, Brendan Bunting PhD, Jose Miguel Caldas de Almeida MD, PhD, Graça Cardoso MD, PhD, Somnath Chatterii MD, Alfredo H. Cia MD, Louisa Degenhardt PhD, Koen Demyttenaere MD, PhD, Silvia Florescu MD, PhD, Giovanni de Girolamo MD, Oye Gureje MD, DSc, FRCPsych, Josep Maria Haro MD, PhD, Hristo Hinkov MD, PhD, Chi-yi Hu MD, PhD, Peter de Jonge PhD, Aimee Nasser Karam PhD, Elie G. Karam MD, Norito Kawakami MD, DMSc, Ronald C. Kessler PhD, Andrzej Kiejna MD, PhD, Viviane Kovess-Masfety MD, PhD, Sing Lee MB, BS, Jean-Pierre Lépine MD, Daphna Levinson PhD, John McGrath MD, PhD, Maria Elena Medina-Mora PhD, Zeina Mneimneh PhD, Jacek Moskalewicz PhD, Fernando Navarro-Mateu MD, PhD, Marina Piazza MPH, ScD, Jose Posada-Villa MD, Kate M. Scott PhD, Tim Slade PhD, Juan Carlos Stagnaro MD, PhD, Dan J. Stein FRCPC, PhD, Margreet ten Have PhD, Yolanda Torres MPH, Dra HC, Maria Carmen Viana MD, PhD, Harvey Whiteford MBBS, PhD, David R. Williams $\mathrm{MPH}, \mathrm{PhD}$ and Bogdan Wojtyniak ScD.

\section{References}

1. Degenhardt L., Glantz M., Evans-Lacko S., Sadikova E., Sampson N., Thornicroft G. et al. Estimating treatment coverage for people with substance use disorders: an analysis of data from the world mental health surveys. World Psychiatry 2017; 16: 299-307.

2. Global Burden of Disease (GBD) 2016 Risk Factors Collaborators. Global, regional, and national comparative risk assessment of 84 behavioural, environmental and occupational, and metabolic risks or clusters of risks, 1990-2016: a systematic analysis for the Global Burden of Disease Study 2016. Lancet Glob Health 2017; 390: 1345-422.

3. Andrews G., Issakidis C., Sanderson K., Corry J., Lapsley H. Utilising survey data to inform public policy: comparison of the cost-effectiveness of treatment of ten mental disorders. Br J Psychiatry 2004; 184: 526-33.

4. Wang P. S., Lane M., Olfson M., Pincus H. A., Wells K. B., Kessler R. C. Twelve-month use of mental health services in the United States: results from the National Comorbidity Survey Replication. Arch Gen Psychiatry 2005; 62: 629-40.

5. Kohn R., Saxena S., Levav I., Saraceno B. The treatment gap in mental health care. Bull World Health Organ 2004; 82: 858-66.

6. Gates P. J., Sabioni P., Copeland J., Le Foll B., Gowing L. Psychosocial interventions for cannabis use disorder. Cochrane Database Syst Rev 2016; 5: CD005336.

7. Edlund M. J., Booth B. M., Han X. Who seeks care where? Utilization of mental health and substance use disorder treatment in two national samples of individuals with alcohol use disorders. J Stud Alcohol Drugs 2012; 73: 635-46.
8. Grella C. E., Karno M. P., Warda U. S., Moore A. A., Niv N. Perceptions of need and help received for substance dependence in a national probability sample. Psychiatr Serv 2009; 60: $1068-74$.

9. Urbanoski K., Inglis D., Veldhuizen S. Service use and unmet needs for substance use and mental disorders in Canada. Can J Psychiatry 2017; 62: 551-9.

10. Harris K. M., Edlund M. J. Use of mental health care and substance abuse treatment among adults with co-occurring disorders. Psychiatr Serv 2005; 56: 954-9.

11. Kessler R. C., Nelson C. B., McGonagle K. A., Edlund M. J., Frank R. G., Leaf P. J. The epidemiology of co-occurring addictive and mental disorders: implications for prevention and service utilization. Am J Orthopsychiatry 1996; 66: 17-31.

12. Teesson M., Slade T., Mills K. Comorbidity in Australia: findings of the 2007 National Survey of mental health and wellbeing. Aust NZ J Psychiatry 2009; 43: 606-14.

13. Morisano D., Babor T. F., Robaina K. A. Co-occurrence of substance use disorders with other psychiatric disorders: implications for treatment services. Nord Stud Alcohol Drugs 2014; 31: 5-25.

14. Watkins K. E., Hunter S. B., Burnam M. A., Pincus H. A., Nicholson G. Review of treatment recommendations for persons with a co-occurring affective or anxiety and substance use disorder. Psychiatr Serv 2005; 56: 913-26.

15. Han B., Compton W. M., Blanco C., Colpe L. J. Prevalence, treatment, and unmet treatment needs of US adults with mental health and substance use disorders. Health Aff (Millwood) 2017; 36: 1739-47.

16. Choi N. G., DiNitto D. M., Marti C. N. Treatment use, perceived need, and barriers to seeking treatment for substance abuse and mental health problems among older adults compared to younger adults. Drug Alcohol Depend 2014; 145: 113-20.

17. Manuel J. I., Setebbins M. B., Wu E. Gender differences in perceived unmet treatment needs among persons with and without co-occurring disorders. J Behav Health Serv Res 2016; 45: 1-12.

18. Ali M. M., Teich J. L., Mutter R. The role of perceived need and health insurance in substance use treatment: implications for the affordable care act. J Subst Abuse Treat 2015; 54: 14-20.

19. Watkins K. E., Paddock S. M., Hudson T. J., Ounpraseuth S., Schrader A. M., Hepner K. A. et al. Association between quality measures and mortality in individuals with co-occurring mental health and substance use disorders. J Subst Abuse Treat 2016; 69: 1-8.

20. Hepner K. A., Paddock S. M., Watkins K. E., Ounpraseuth S. T., Schrader A. M., Hudson T. J. Association between quality measures and perceptions of care among patients with substance use disorders. Psychiatr Serv 2017; 68: 1150-6.

21. Schmidt E. M., Gupta S., Bowe T., Ellerbe L. S., Phelps T. E., Finney J. W. et al. Predictive validity of a quality measure for intensive substance use disorder treatment. Subst Abuse 2017; 38: 317-23.

22. Harkness J., Pennell B., Villar A., Gebler N., Aguilar-Gaxiola S., Bilgen I. Translation procedures and translation assessment in the World Mental Health Survey initiative. In: Kessler R. C., Üstün T. B., editors. The WHO World Mental Health Surveys: Global Perspectives on the Epidemiology of Mental Disorders. New York: Cambridge University Press; 2008, pp. 91-113.

23. Mohler P., Dorer B., de Jong J., Hu M. Translation: Overview. Guidelines for Best Practice in Cross-Cultural Surveys. Ann Arbor, MI: Survey Research Center, Institute for Social Research, University of Michigan; 2016, pp. 233-85. 
24. Heeringa S. G., Wells J. E., Hubbard F., Mneimneh Z., Chiu W. T., Sampson N. et al. Sample designs and sampling procedures. In: Kessler R. C., Ustun T. B., editors. The Who World Mental Health Surveys: Global Perspectives On the Epidemiology of Mental Disorders. New York: Cambridge University Press; 2008, pp. 14-32.

25. Lee S., Tsang A., Breslau J., Aguilar-Gaxiola S., Angermeyer M., Borges G. et al. Mental disorders and termination of education in high-income and low- and middle-income countries: epidemiological study. Br J Psychiatry 2009; 194: 411-7.

26. Morley K. C., Teesson M., Reid S. C., Sannibale C., Thomson C., Phung N. et al. Naltrexone versus acamprosate in the treatment of alcohol dependence: a multi-centre, randomized, double-blind, placebo-controlled trial. Addiction 2016; 101: 1451-62.

27. Oleski J., Mota N., Cox B. J., Sareen J. Perceived need for care, help seeking, and perceived barriers to care for alcohol use disorders in a national sample. Psychiatr Serv 2010; 61: 1223-31.

28. Kessler R. C., Chiu W. T., Demler O., Merikangas K. R., Walters E. E. Prevalence, severity, and comorbidity of 12-month DSMIV disorders in the National Comorbidity Survey Replication. Arch Gen Psychiatry 2005; 62: 617-27.

29. Killeen T. K., Brady K. T., Gold P. B., Tyson C., Simpson K. N. Comparison of self-report versus agency records of service utilization in a community sample of individuals with alcohol use disorders. Drug Alcohol Depend 2004; 73: 141-7.

30. Glass J. E., Bucholz K. K. Concordance between self-reports and archival records of physician visits: a case-control study comparing individuals with and without alcohol use disorders in the community. Drug Alcohol Depend 2011; 116: 57-63.

31. Beebe T. J., McRae J. A., Barnes S. A. A comparison of selfreported use of behavioral health services with Medicaid agency records in Minnesota. Psychiatr Serv 2006; 57: 1652-4

32. Reif S., Horgan C. M., Ritter G. A. Treatment services: triangulation of methods when there is no gold standard. Subst Use Misuse 2011; 46: 620-32.

33. Chung S., Domino M. E., Jackson E. W., Morrissey J. P. Reliability of self-reported health service use: evidence from the women with co-occurring disorders, and violence study. $J$ Behav Health Serv Res 2008; 35: 265-78.

34. Rehm J., Anderson P., Manthey J., Shield K. D., Struzzo P., Wojnar M. et al. Alcohol use disorders in primary health care: what do we know and where do we go? Alcohol Alcohol 2016; 51: 422-7.

35. Scott K. M., Lim C., Al-Hamzawi A., Alonso J., Bruffaerts R., Caldas-de-Almeida J. M. et al. Association of Mental Disorders with Subsequent Chronic Physical Conditions. World mental health surveys from 17 countries. JAMA Psychiatry 2016; 73: $150-8$.

36. Thornicroft G., Chatterji S., Evans-Lacko S., Gruber M., Sampson N., Aguilar-Gaxiola S. et al. Undertreatment of people with major depressive disorder in 21 countries. $\mathrm{Br} J$ Psychiatry 2017; 210: 119-24.

37. Edlund M. J., Booth B. M., Feldman Z. L. Perceived need for treatment for alcohol use disorders: results from two national surveys. Psychiatr Serv 2009; 60: 1618-28.

38. Klimas J. Training in addiction medicine should be standardised and scaled up. BMJ 2015; 351: h4027.

39. Salwan J., Katz C. L. A review of substance use disorder treatment in developing world communities. Ann Glob Health 2014; 80: 115-21.
40. Mojtabai R., Chen L.-Y., Kaufmann C. N., Crum R. M. Comparing barriers to mental health treatment and substance use disorder treatment among individuals with comorbid major depression and substance use disorders. J Subst Abuse Treat 2014; 46: 268-73.

41. Saunders S. M., Zygowicz K. M., D’Angelo B. R. Person-related and treatment-related barriers to alcohol treatment. J Subst Abuse Treat 2006; 30: 261-70.

42. Schuler M. S., Puttaiah S., Mojtabai R., Crum R. M. Perceived barriers to treatment for alcohol problems: a latent class analysis. Psychiatr Serv 2015; 66: 1221-8.

43. Luitel N. P., Jordans M. J. D., Kohrt B. A., Rathod S. D., Komproe I. H. Treatment gap and barriers for mental health care: a cross-sectional community survey in Nepal. PLOS ONE 2017; 12: e0183223.

44. Crowley R., Kirschner N., Dunn A. S., Bornstein S. S. Health and public policy to facilitate effective prevention and treatment of substance use disorders involving illicit and prescription drugs: an American College of Physicians position paper. Ann Intern Med 2017; 166: 733-6.

45. Eaton J., McCay L., Semrau M., Chatterjee S., Baingana F., Araya R. et al. Scale up of services for mental health in lowincome and middle-income countries. Lancet 2011; 378: 1592-603.

46. McDaid D., Knapp M., Raja S. Barriers in the mind: promoting an economic case for mental health in low- and middleincome countries. World Psychiatry 2008; 7: 79-86.

47. Benegal V., Chand P. K., Obot I. S. Packages of care for alcohol use disorders in low-and middle-income countries. PLOS Med 2009; 6: e1000170.

48. Alonso J., Liu Z., Evans-Lacko S., Sadikova E., Sampson N., Chatterji S. et al. Treatment gap for anxiety disorders is global: results of the world mental health surveys in 21 countries. Depress Anxiety 2018; 35: 195-208.

49. Urbanoski K. A., Rush B. R., Wild T. C., Bassani D. G., Castel S. Use of mental health care services by Canadians with cooccurring substance dependence and mental disorders. Psychiatr Serv 2007; 58: 962-9.

50. Tuithof M., Ten Have M., Van Den Brink W., Vollebergh W., De Graaf R. Treatment seeking for alcohol use disorders: treatment gap or adequate self-selection? Eur Addict Res 2016; 22: 277-85.

51. Grella C., Stein J. Remission from substance dependence: differences between individuals in a general population longitudinal survey who do and do not seek help. Drug Alcohol Depend 2013; 133: 146-53.

52. Larney S., Peacock A., Leung J., Colledge S., Hickman M., Vickerman P. et al. Global, regional, and country-level coverage of interventions to prevent and manage HIV and hepatitis $\mathrm{C}$ among people who inject drugs: a systematic review. Lancet Glob Health 2017; 5: e1208-e1220.

53. Dua T., Barbui C., Clark N., Fleischmann A., Poznyak V., van Ommeren M. et al. Evidence-based guidelines for mental, neurological, and substance use disorders in low- and middleincome countries: summary of WHO recommendations. PLOS Med 2011; 8: e1001122.

54. World Health Organization (WHO). mhGAP Intervention Guide for Mental, Neurological and Substance Use Disorders in NonSpecialized Health Settings: Mental Health GAP Action Programme (mhGAP). Geneva: WHO; 2010.

55. Shidhaye R., Lund C., Chisholm D. Closing the treatment gap for mental, neurological and substance use disorders by strengthening existing health care platforms: strategies for 
delivery and integration of evidence-based interventions. Int J Ment Health Syst 2015; 9: 40.

56. Petersen I., Evans-Lacko S., Semrau M., Barry M. M., Chisholm D., Gronholm P. et al. Promotion, prevention and protection: interventions at the population- and community-levels for mental, neurological and substance use disorders in low- and middle-income countries. Int J Ment Health Syst 2016; 10: 30.

57. United Nations. Transforming Our World: the 2030 Agenda for Sustainable Development. Resolution of the United Nations General Assembly. New York: United Nations; 2015.

\section{Supporting Information}

Additional supporting information may be found online in the Supporting Information section at the end of the article.

Table S1 Bivariate association of comorbid mental disorder on substance use disorder treatment and minimally adequate treatment among all respondents with past-year substance use disorder, overall and broken down by country income group.

Table S2 Logistic regression results investigating variables associated with receiving "any' and 'minimally adequate" 12 -month substance use disorder treatment $(N=2446)$.

Table S3 Logistic regression results investigating variables associated with receiving treatment from a healthcare professional among those with any 12-month substance disorder treatment $(N=300)$.

Table S4 Logistic regression results investigating variables associated with receiving 'any" and "minimally adequate" treatment from a healthcare professional; excluding those that received only non-healthcare treatment $(N=2402)$.
Table S5 Logistic regression results investigating variables associated with receiving "any" and "minimally adequate" treatment from a non-healthcare professional; excluding those that received any healthcare treatment $(N=2190)$. Table S6 Multivariable logistic regression results investigating variables associated with receiving 'any' and 'minimally adequate' 12-month substance use disorder treatment; separated into Low/Middle and High income countries.

Table S7 Multivariable logistic regression results investigating variables associated with receiving healthcare treatment among those with any 12-month substance disorder treatment; separated into Low/Middle and High income countries.

Table S8 Multivariable logistic regression results investigating variables associated with receiving 'any" and "minimally adequate 12 month substance use disorder treatment from a healthcare professional; separated into Low/Middle and High income surveys and excluding those that received only non-healthcare treatment.

Table S9 Multivariable logistic regression results investigating variables associated with receiving 'any" and "minimally adequate 12-month substance use disorder treatment from a non-healthcare professional; limited to High income surveys ${ }^{\mathrm{a}}$ and excluding those that received any healthcare treatment.

Table S10 Logistic regression results investigating the interactive effect of healthcare professional with all socio-demographic variables on receiving minimally adequate treatment ${ }^{\mathrm{a}}$. 